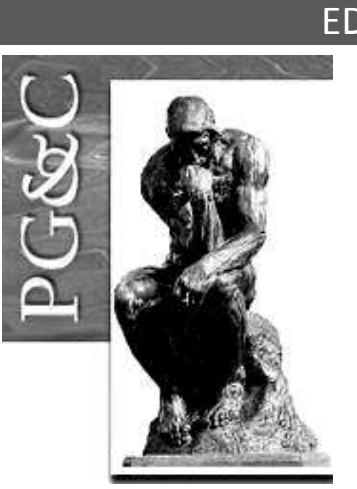

\title{
OS IMPACTOS DA PANDEMIA DE COVID-19 E A RESPOSTA DOS PERIÓDICOS CIENTÍFICOS
}

Chegamos ao fim de 2020 ainda sob os auspícios da presença da pandemia do novo Coronavírus SARS-CoV-2 que provoca a doença denominada de COVID-19, acompanhando o aumento diário do número de mortes e de casos no Brasil e no mundo, ao tempo que acompanhamos as notícias recentes de variação do vírus, mas também o início da vacinação em partes do mundo, a exemplo da Europa e dos Estados Unidos, algo que almejamos que se inicie no Brasil em 2021 para vencermos a COVID-19.

Uma coisa é certa, ao longo deste ano, a COVID-19 despertou muitos desafios, muitas inquietações e questionamentos por parte da comunidade científica. A partir da crise inimaginável gerada pelo surgimento do novo Coronavírus e da pandemia, nos mais diversos setores, na seara científica incontáveis periódicos, das mais diversas áreas de conhecimento ${ }^{1}$, publicaram edições correntes ou dossiês temáticos em que a tônica dos artigos, relatos de pesquisa e relatos de experiência tinham como fio condutor a COVID-19, evidenciando o papel fundamental da ciência, que aliada à tecnologia e à inovação, contribui sobremaneira para o enfrentamento desta pandemia, "para os desafios de saúde atuais, assim como para a recuperação do mundo após a pandemia" como adverte Franciele Garcia (ACADEMIA BRASILEIRA DE CIÊNCIAS, 2020, online).

Especificamente no caso das Ciências Sociais e Humanas, estas "têm nesse cenário, um papel fundamental para achar soluções de acesso democrático a direitos para que todos tenham uma vida digna", conforme destaca Pedro Wongtscowski (ACADEMIA BRASILEIRA DE CIÊNCIAS, 2020, online), portanto as perspectivas e os desafios acerca das questões como Fake News ou desinformação, infodemia, desinfodemia, informação pública, pós-verdade, direitos humanos e vulnerabilidades, competências, mundo trabalho em tempo de pandemia, dentre outras inúmeras questões, estão na ordem do dia dos periódicos das respectivas áreas, conforme suas especialidades e fenômenos de estudo em linha com as transformações do mundo contemporâneo.

A PG\&C, cumprindo a sua missão e o rigor da sua periodicidade, mesmo não trazendo uma edição específica sobre os impactos da COVID-19, porém sendo citados transversalmente em um ou outro artigo, coloca à disposição dos leitores o volume 10, número 3 de setembro a dezembro de 2020. Esta edição traz um Artigo de revisão, 12 Relatos de pesquisa e um Relato de Experiência, além deste Editorial e do Expediente. Constituem os itens publicados as seguintes temáticas: implementação de um modelo de gestão do conhecimento, Aderências às práticas de gestão, Competências

\footnotetext{
${ }^{1}$ A título de exemplo, na área da Ciência da Informação, citamos a Liinc em Revista que é editada pelo Instituto Brasileiro de Informação em Ciência e Tecnologia (IBICT) e por seu Programa de Pós-Graduação em Ciência da Informação, desenvolvido em parceria com a Universidade Federal do Rio de Janeiro (UFRJ).Disponível em: http://revista.ibict.br/liinc/issue/view/298
}

Perspectivas em Gestão \& Conhecimento, João Pessoa, v. 10, n. 3, p. 1-2, set./dez. 2020. DOI: https://dx.doi.org/10.22478/ufpb.2236-417X.2020v10n3.57034 http://periodicos.ufpb.br/ojs2/index.php/pgc. ISSN: 2236-417X. Publicação sob Licença 
gerenciais, Gestão de ideias, Smart Campus, Transparência de Portais Eletrônicos, dentre outras temáticas no âmbito do escopo da revista.

Como últimas palavras, desejamos profícua leitura e, o mais importante, desejamos um Ano Novo de saúde e de esperanças renovadas, com vacina em 2021!

Esperamos continuar contando com a sua confiança no ano vindouro.

João Pessoa, Paraíba, Brasil, 29 de dezembro de 2020.

Os Editores

Luciana Ferreira da Costa e Jorge de Oliveira Gomes

https://twitter.com/revistapgecufpb

\section{REFERÊNCIAS}

ACADEMIA BRASILEIRA DE CIÊNCIAS. O mundo a partir do Coronavírus: ciência, inovação e COVID-19. 2020. Disponível em: http://www.abc.org.br/2020/06/15/o-mundo-a-partir-docoronavirus-ciencia-inovacao-e-covid-19/. Acesso em: 20 jun. 2020. 